\title{
HEART RATE RECOVERY CHANGES FOR HIGH CLASS CANOE SPRINT ATHLETES DURING DIFFERENT TRAINING PERIODS
}

\author{
Martins Veispals \\ Latvian Academy of Sport Education, Latvia \\ Antra Gulbe \\ Latvian Academy of Sport Education, Latvia \\ Andris Konrads \\ Latvian Academy of Sport Education, Latvia
}

\begin{abstract}
One of the criteria for exercise intensity in sport science is heart rate. Reduced heart rate in exercise indicates heart's ability to work more effectively. 12 high class flat-water kayakers (Latvian national team members) took part in this study. The main aims of the study were to evaluate the improvements of the heart regeneration rate and the functional condition of the athletes over the time period of 4 years - where all participant repeated a maximum oxygen consumption test on rowing ergometer 43 times (2-6 times per athlete). Heart rate recovery drop was obtained in the first 4 minutes after the maximum oxygen consumption test. For reflection on functional condition, speed on kayak ergometer at lactate concentration in blood values of $1 \mathrm{mmol} / \mathrm{l}$ and $3 \mathrm{mmol} / \mathrm{l}$ was measured (low-intensity load and submaximal intensity load). Speed on kayak ergometer at a blood lactate value $3 \mathrm{mmol} / \mathrm{l}$ show an average increase of $0.96 \mathrm{~km} / \mathrm{h}$ (By Student's $t$ - test for related samples and Wilcoxon's criteria). For heart rate regeneration Wilcoxon's criterion shows an average increase of $0.46 \%$.
\end{abstract}

Keywords: anaerobic threshold, heart rate, heart rate recovery, lactate concentration.

\section{Introduction}

Heart rate is the governing indicator of the development and physical condition of the cardiovascular system. It is easy to determine the heart rate at any given time by reading the pulse on the arteries of the palms. If the heart rate is in the average range (not excessively high) it shows that the heart performs a normal blood-pumping function and ensures oxygen transportation to the cells. In sports practice, heart rate is widely used as an evaluation criterion for load intensity (Karvonen \& Vuorimma, 1988; Iwasaki, Zhang, Zuckerman, \& Levine 2003; Banister \& Calvert, 1980; Bourdon et al., 2017).

The heart rate reflects the amount of the work heart needs to do during the exercise and in a steady state. Furthermore, it can indicate disorders in the body's regulatory system if the heart rate is increased or with an uneven rhythm. 
With the development of technologies, various heart rate receivers (sport watches, straps, bracelets, etc.) have become more popular (Laukkanen \& Virtanen, 1998; Nims, Capozzi, Hailey, \& Crankson, 2018). Therefore, the intensity and heart rate during the exercise usually is measured by these devices. The data obtained can be saved and analysed for a proper adaption of the training loads and recovery.

\section{Literature review}

In the last decades several studies have been conducted (Carter, Banister, \& Blaber, 2003; Yamamoto, Myachi, Saitoh, Yoshioka, \& Onodera, 2001; Greiwe et al., 1999; Smith, Hudson, Graitzer, \& Raven, 1989; Amano, Kanda, UE, \& Moritani, 2001; Lambert, \& Borresen, 2010) about the heart rate and the impacts of endurance training on that. It is essential to study this phenomenon more extendedly in high class athletes.

The studies performed by (Wilmore et al., 1996) shows that after a 6-month period of moderate endurance training heart rate is reduced by 10-30 beats per minute. With higher intensity endurance training, heart rate drops even more. Since the heart rate regeneration period becomes shorter as a result of endurance training, it is considered being a cardiovascular conditioner. Therefore, after standardized exercise, a physically advanced person recovers faster than a physically weaker person (Seiler, Haugen, \& Kuffel, 2007). However, not only does physical capability affect heart rate recovery. Exercise at elevated temperatures or high above the sea level may prolong the heart rate recovery period (Lambert, Mbambo, \& Gibson, 1998). Also, the duration of the recovery may be affected by a stronger sympathetic nervous system reaction (Shin, Minamitani, Onishi, Yamazaki, \& Lee, 1995a, 1995b; Dixon, Kamath, McCartney, \& Fallen, 1992; Kannankeril, Le, Kadish, \& Goldberger, 2004).

The reduced heart rate under loads indicates the heart's ability to work more effectively as a result of the training. To perform the necessary functions, a trained heart will do much less work than an untrained heart. Studies by (Borg \& Linderholm, 1967; Skinner, 1973; Stamford, 1976; Eston \& Williams, 1986) confirm that there is a linear relationship between heart rate and load intensity.

Sports researcher Platonov (2004) analysed high class athletes. This study concluded that training load has different effects on the heart rate recovery of athletes depending on physical condition. For athletes with higher physical condition, the training load does not cause significant changes in the body, but for athletes with weaker physical conditions on the contrary. Moreover, the recovery process after peak load is faster for higher class athletes. 
It is important to view high-class athlete's heart rate regeneration performance for the purpose to improve an athlete's health and optimisation of the training processes.

\section{Outline}

In the present paper, the data obtained of the heart rate regeneration after maximal oxygen consumption load tests and functional condition assessment (by power/speed demonstrated on ergometer) of professional flat-water kayakers are presented. The aims of the study were to evaluate the improvements of the heart regeneration rate and the functional condition of the athletes over the time period of 4 years. To determine heart rate regeneration and functional condition improvements of the athletes, speed on ergometer was determined on the lactate concentration in the blood (3 $\mathrm{mmol} / \mathrm{l})$. Moreover, to evaluate the heart rate recovery changes over the time period the mathematical statistics such as the Wilcoxon criterion and T-test were used.

\section{Methodology}

The test subjects were 12 professional (high class) flat-water kayakers. The duration of the study was 4 years, where all participant repeated a maximum oxygen consumption test on rowing ergometer 43 times (2-6 times per athlete). All tests were performed in the Latvian Olympic Laboratory (LOV). The data was collected from different measuring tools, such as ergometry, heart rate monitoring, and blood lactate measurements during the test phases. The physical condition of the test subject in each test was different and depended on training cycles. The results of the study were processed with the RStudio application - an integrated development environment (IDE) for $\mathrm{R}$ (programming language), a programming language for statistical computing and graphics. The following values were obtained: average arithmetic, standard deviation, variation coefficient, standard error, an average increase, an empirical value of the student's T-test, T-theoretical value for mutual distribution, T-theoretical value for onesided distribution.

\section{Maximum oxygen consumption test}

The maximum oxygen consumption test was performed on a kayak ergometer "Dansprint" (Dansprint.com, n. d.). This type of kayak ergometer provides the closest possible sense of the paddling in the water. The ergometer can simulate speed up to $18 \mathrm{~km} / \mathrm{h}$. Furthermore, it measures breaking load on the 
flywheel and accumulates kinetic energy, thereby determining the athlete's workload.

The heart rate was determined with the company's Polar RS 800 heart rate monitor (Support. polar.com, n. d.) and electrocardiogram. The pulse meter strap was used to verify data from electrocardiogram measurements.

The lactate levels in the blood were measured with a BiosenC (HaB Direct, n. d.) line equipment. This type of apparatus measures both glucose and lactate levels in the blood. BiosenC apparatus is based on a special chip sensor technology and provides fast and high precision measurements. The measurements of the blood lactate levels take up to 25 seconds and only $20 \mu \mathrm{l}$ of the blood is required for the measurement.

The tests begin with the anthropometric measurements and weighting of the athletes. The resting heart rate, blood pressure, respiratory test and lung volume measurements were performed. Before the maximum oxygen consumption tests the athletes performs cardiopulmonary stress test (abbr. CST). (no data or results from CST are discussed in this paper). The CST duration is up to 7 minutes. The heart rate, blood pressure and lactate concentration in the blood are measured. After the CST is a 5 minute recovery, resting period. Subsequently, athlete goes to kayak ergometer and paddles up to the anaerobic threshold (the test is interrupted after a rapid rise of lactate concentration in the blood and oxygen consumption). Then follows a 5-minute resting period. At the end of the 5-minute recovery period, the test continues with 8 intervals (see Table 1 ).

Table 1 Description of intervals

\begin{tabular}{|c|c|c|c|}
\hline Interval number & Duration time, $(\mathrm{sec})$ & Rest time, (sec) & Speed, $(\mathrm{km} / \mathrm{h})$ \\
\hline 1. & 40 & \multirow{2}{*}{20} & 11.5 \\
\hline 2. & 40 & & 12.0 \\
\hline \multirow{2}{*}{3.} & \multirow{2}{*}{40} & 20 & \multirow{2}{*}{12.5} \\
\hline & & \multirow{2}{*}{20} & \\
\hline 4. & 40 & & 13.0 \\
\hline \multirow{2}{*}{5.} & \multirow{2}{*}{40} & 80 & \multirow{2}{*}{13.0} \\
\hline & & \multirow{2}{*}{20} & \\
\hline 6. & 40 & & 13.5 \\
\hline 7. & 40 & 20 & 14.0 \\
\hline \multirow{2}{*}{8.} & \multirow{2}{*}{$200 \mathrm{~m}$} & 20 & \multirow{2}{*}{ max with time control } \\
\hline & & & \\
\hline
\end{tabular}


The blood pressure, lactate levels and heart rate are measured at every minute. After intervals athletes have a 5-minute recovery period, followed with a 20-minute cool down, or more, if needed. Every 5 minutes the blood lactate is measured to control recovery of the athletes.

Heart rate recovery changes were determined in the first 4 minutes after the maximum oxygen consumption test. The data of the maximum heart rate, heart rate on the 1st recovery minute, heart rate on the 2nd recovery minute, heart rate on the 3rd recovery minute and heart rate on the 4th recovery minute were collected. Every minute heart rate drops, and total heart rate drops were determined for all athletes and analysed.

To determine the improvement of the functional condition of athletes the heart rate and speed values were collected at the fixed levels of test loads (governed by blood pressure and lactate concentration in blood). Speed on kayak ergometer at lactate concentration in blood values of $1 \mathrm{mmol} / \mathrm{l}$ and $3 \mathrm{mmol} / \mathrm{l}$ was fixed (low-intensity load and submaximal intensity load). Furthermore, to evaluate functional condition of the speed on the kayak ergometer was measured at lactate concentration of $3 \mathrm{mmol} / \mathrm{l}$. In practice, there are lots of opinions between sports researchers. Kindermann, Simon, \& Keul (1979) made a conclusion that high impact on endurance can be gained by training in the range of $2 \mathrm{mmol} / \mathrm{l}$ lactate. Range from 2 to $4 \mathrm{mmol} / \mathrm{l}$ lactate are considered the aerobic - anaerobic transition range. $4 \mathrm{mmol} / \mathrm{l}$ lactate - the anaerobic threshold (Baldari \& Guidetti, 2000). The concept of the aerobic-anaerobic transition as a framework was used for performance diagnosis and training prescription in endurance sports (Faude, Kindermann, \& Meyer, 2009). Since 1979, this framework has been adopted, applied and refined by several researchers (Skinner \& Mclelan, 1980; Stegmann \& Kindermann, 1982; Faria, Parker, \& Faria, 2005; Jones 2006; Mann, Lamberts, \& Lambert, 2013). Since $3 \mathrm{mmol} / \mathrm{l}$ lactate for most individuals are considered as mixed aerobic - anaerobic transition range it was confided as a suitable value to measure athletes progress.

\section{Results}

The results of the study are presented in two parts: heart rate recovery changes and functional condition of the athletes. The data from measurements is analysed with descriptive statistics.

\section{Heart rate recovery changes}

The data of 43 tests is presented in Figure 1. Figure 1 shows heart rate recovery changes for every athlete in the studies. 
Veispals et al., 2020. Heart Rate Recovery Changes for High Class Canoe Sprint Athletes During Different Training Periods
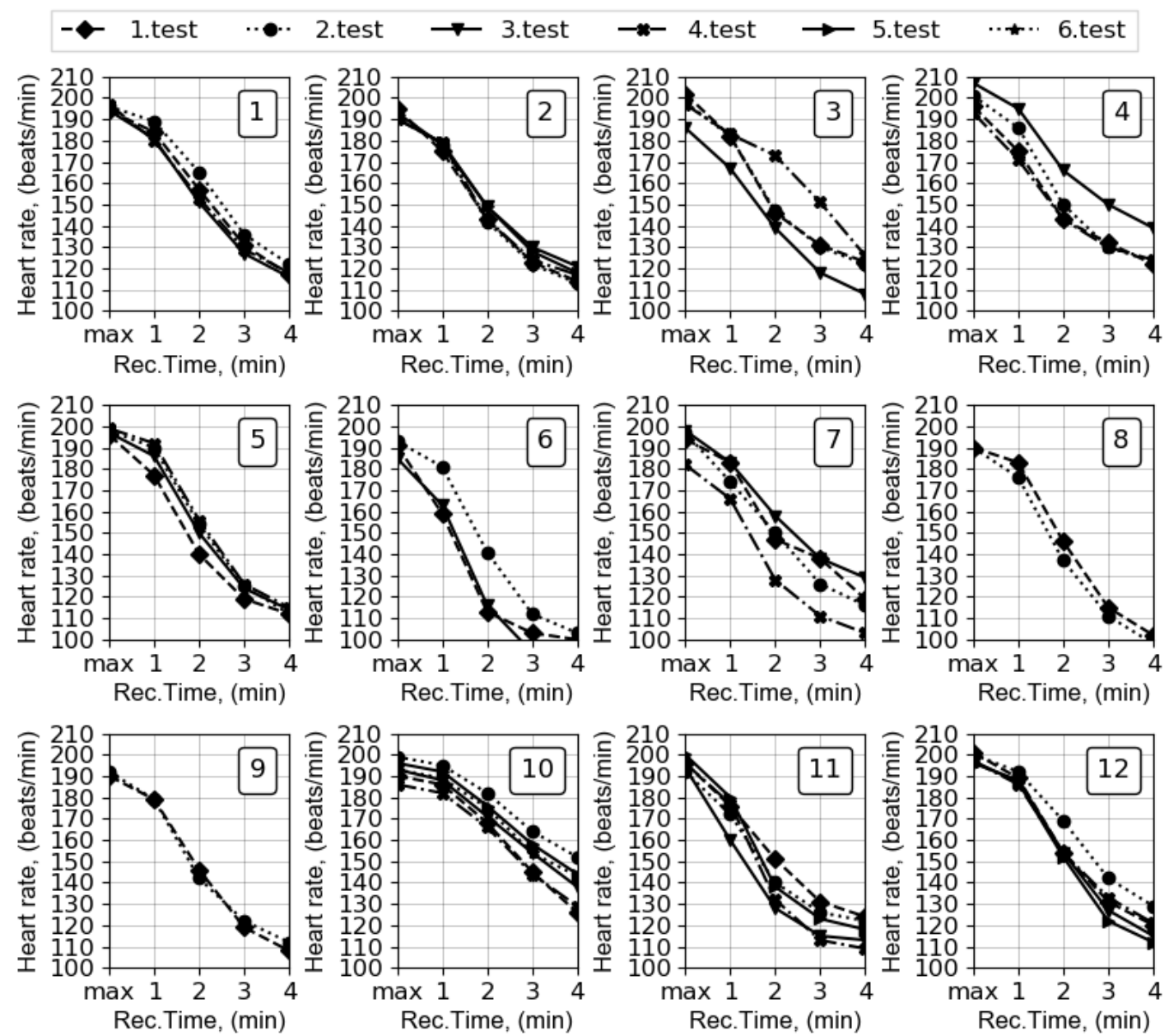

Figure 1 Heart rate recovery changes for every athlete in the studies

(1) $1^{\text {st }}$ athlete, (2) $2^{\text {nd }}$ athlete, (3) $3^{\text {rd }}$ athlete, (4) $4^{\text {th }}$ athlete, (5) $5^{\text {th }}$ athlete, (6) $6^{\text {th }}$ athlete, (7) $7^{\text {th }}$ athlete, (8) $8^{\text {th }}$ athlete, (9) $9^{\text {th }}$ athlete, (10) $10^{\text {th }}$ athlete, (11) $11^{\text {th }}$ athlete, (12) $12^{\text {th }}$ athlete

The data in Figure 1 shows that the maximal heart rate for every test subject is in the range from 189 to 200 beats $/ \mathrm{min}$, except for the $4^{\text {th }}$ athlete in test 3 the maximal heart rate was 207 beats $/ \mathrm{min}$. The changes in reaching the maximal hearth rate for each test subject are in limits $+/-4$ percent between performed tests. Furthermore, all test subjects reached similar maximal heart rate readings. The heart rate frequency curve after the load for all test subjects are similar and the slopes steepness is non-linear.

In order to examine heart rate recovery, drop more details, the data of heart rate decrease in each minute were collected (see Figure 2). From the maximum HR value till 1st minute, from 1st minute to 2nd minute, from 2nd to 3rd minute and from 3rd to 4th minute. The total HR drop was also calculated - total decrease in beats/min from maximum HR till HR of the $4^{\text {th }}$ recovery minute. 


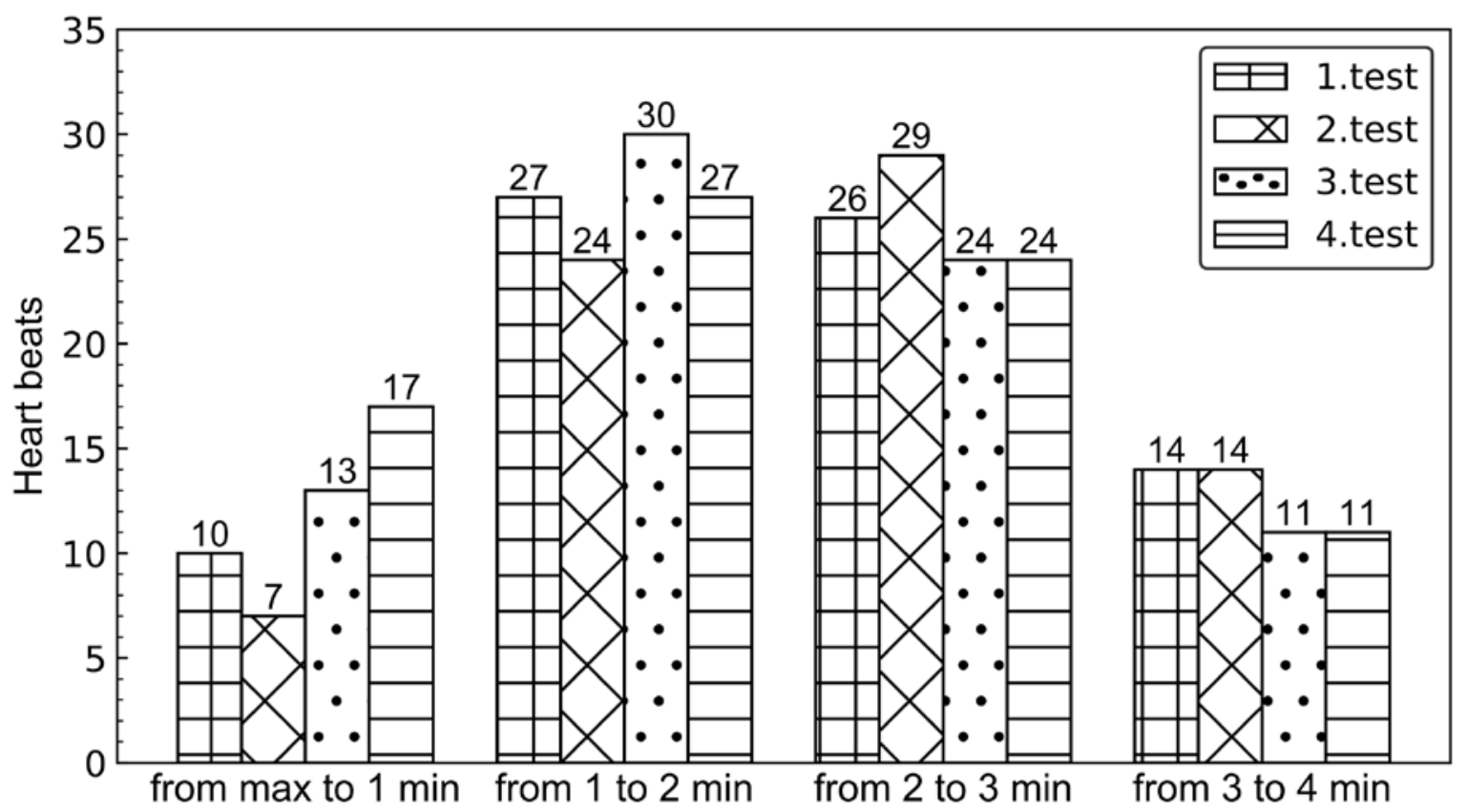

Figure 2 1st athlete's heart rate drops in every minute

Figure 2 shows the data of the $1^{\text {st }}$ athlete's heart rate drops in every minute through four tests. The drops of the heart rate do not increase from test to test, but it fluctuates in a specific interval for every recovery minute. The first and fourth recovery minutes give the lowest heart rate drops, and they are in limits from 7 to 17 beats/min. Moreover, the second and third minutes give the highest heart rate drops from 24 to 30 beats/min. The heart rate drops in second and third minutes is almost twice as high as in the first and fourth minutes. As it can be seen, the third test in which the athlete made the highest speed on kayak ergometer at lactate $3 \mathrm{mmol} / \mathrm{l}$ not stand out among the rest of the tests performed.

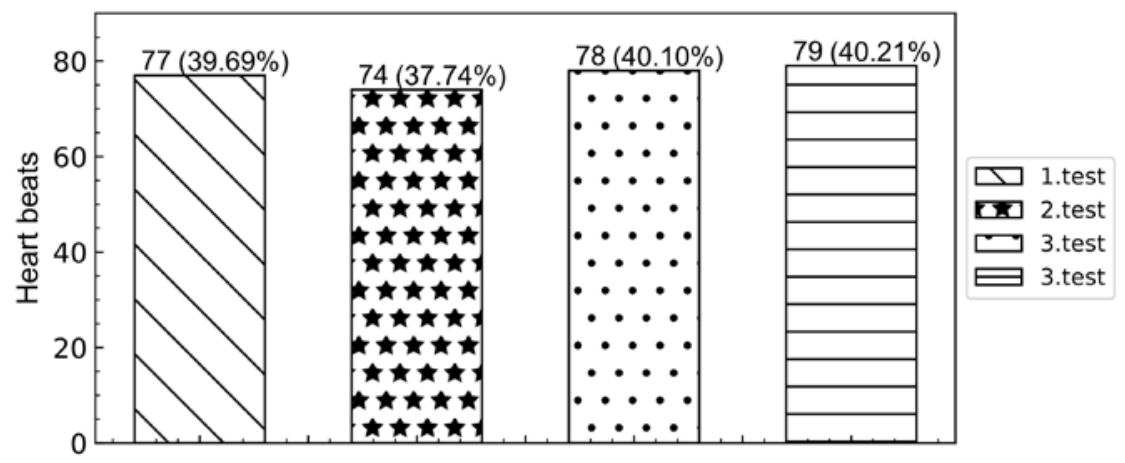

Figure 3 1st athlete's total heart rate drop

Figure 3 shows data for total heart rate drops for the $1^{\text {st }}$ athlete. Heart rate drop in all four tests is in limits from 74 to 79 beats/min; the average total drop is 
77 beats/min. The difference in the lowest total heart rate drop (2nd test) and the highest heart rate drop ( $4^{\text {th }}$ test) converting into percentages is 2.47 percent (see Figure 3). All other test subjects showed similar results with a maximal heart rate drop of the $6^{\text {th }}$ athlete in a $3^{\text {rd }}$ test with 93 beats $/ \mathrm{min}$. Moreover, the lowest maximal heart rate drop was for the $10^{\text {th }}$ athlete in a 2nd test with 47 beats $/ \mathrm{min}$.

The overall percentage drop from the maximum HR until recovery in the 4th minute has a non-linear trend. The highest HR drop is in the $4^{\text {th }}$ test with a 40.21 percent. On other hand, in the $2^{\text {nd }}$ test, when athlete showed the highest speed measurements on the kayak ergometer at lactate $3 \mathrm{mmol} / \mathrm{l}$, the overall percentage drop was $2.05 \%$ lower than in the $1^{\text {st }}$ test. Therefore, non-linear increase in a total drop is observed.

\section{Functional condition}

The functional condition (athletes speed on kayak ergometer) varies depending on the tests. The data of the highest speed and the lowest speed for all twelve athletes at a blood lactate $3 \mathrm{mmol} / \mathrm{l}$ are presented in Figure 4 . The lactate value of $3 \mathrm{mmol} / \mathrm{l}$ was chosen as a close range to anaerobic threshold (Faria, Parker, \& Faria, 2005; Jones 2006; Mann, Lamberts, \& Lambert, 2013).

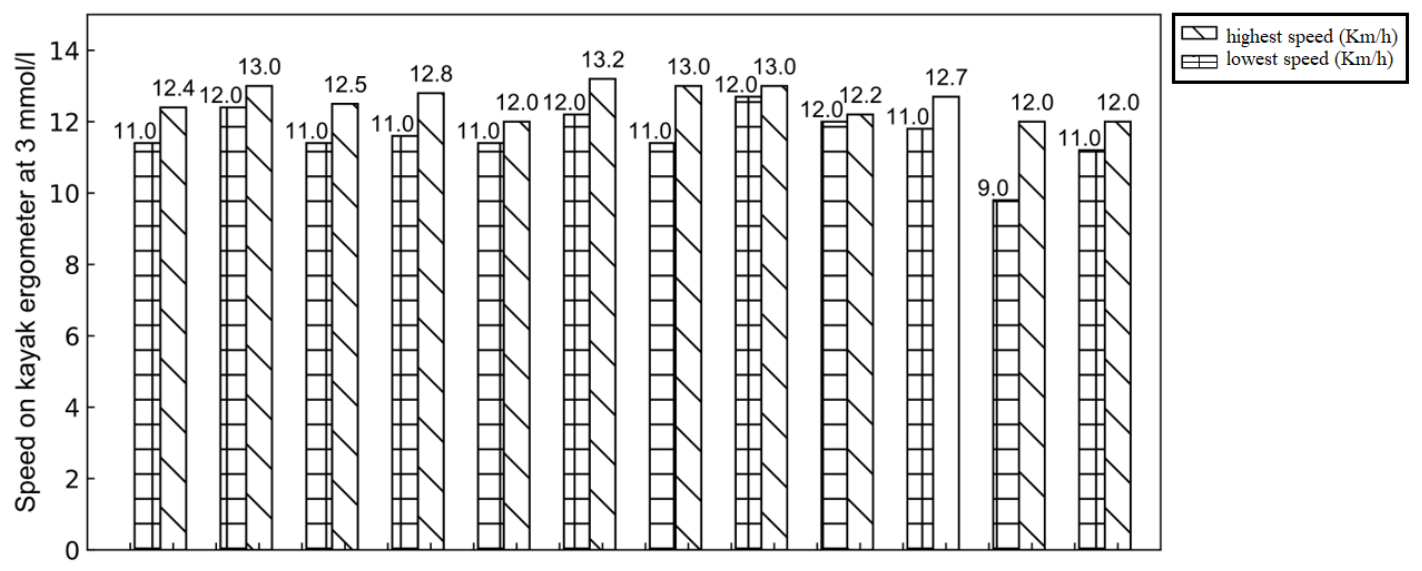

Figure 4 Athletes functional condition (reflected as speed on kayak ergometer on blood lactate value $3 \mathrm{mmol} / \mathrm{l}$ )

The worst and the best speed on the kayak ergometer for each athlete are shown in Figure 4 . The lowest speed from all 43 tests is demonstrated by $11^{\text {th }}$ athlete $-9.8 \mathrm{~km} / \mathrm{h}$. Moreover, this speed value is lower by $1.4 \mathrm{~km} / \mathrm{h}$ from the second lowest speed value. The highest speed on the kayak ergometer is demonstrated by the $6^{\text {th }}$ athlete $-13.2 \mathrm{~km} / \mathrm{h}$. All speed values from the best and the worst vary in limits from $0.2 \mathrm{~km} / \mathrm{h}$ to $2.2 \mathrm{~km} / \mathrm{h}$.

The analysis of the test groups descriptive statistics (see Table 2) shows a variation coefficient value for the highest functional condition of $3.5 \%$ and for the 
SOCIETY. INTEGRATION. EDUCATION

Proceedings of the International Scientific Conference. Volume VI, May $22^{\text {th }}-23^{\text {th }}, 2020.430-444$

lowest $6.3 \%$, thus the group is considered uniform. The speed rate increase on kayak ergometer at a blood lactate $3 \mathrm{mmol} / \mathrm{l}$, varies according the law of a normal distribution.

Table 2 Descriptive statistics of functional condition

\begin{tabular}{|l|c|c|}
\hline & $\begin{array}{c}\text { Lowest } \\
\text { functional } \\
\text { condition }\end{array}$ & $\begin{array}{c}\text { Highest } \\
\text { functional } \\
\text { condition }\end{array}$ \\
\hline Average arithmetic & 11.6 & 12.6 \\
\hline Standard deviation & 0.7 & 0.4 \\
\hline Variation coefficient & $\mathbf{6 . 3 \%}$ & $\mathbf{3 . 5 \%}$ \\
\hline Confidence interval (error probability $<0,05)$ & $11.1-12.1$ & $12.3-12.8$ \\
\hline Asymmetry indicator & -1.077 & -0.108 \\
\hline Asymmetry t-test $(t<3)$ & 1.690 & 0.170 \\
\hline Excess t-test $(t<3)$ & 2.237 & 1.302 \\
\hline Compliance with a normal distribution & yes & yes \\
\hline
\end{tabular}

Since there is compliance with a normal distribution further analysis is possible. The use of Student's t - test for related samples and Wilcoxon's criteria show an average increase of $0.96 \mathrm{~km} / \mathrm{h}$ (see table 3). Both criteria confirm that the increase in value is credible. $t \geq t_{\alpha ; v}$

Table 3 Analysis of Functional Changes by Wilcoxon's Criterion

\begin{tabular}{|l|c|c|}
\hline & $\begin{array}{c}\text { Lowest functional } \\
\text { condition }\end{array}$ & $\begin{array}{c}\text { Best functional } \\
\text { condition }\end{array}$ \\
\hline Average arithmetic & 11.61 & 12.57 \\
\hline Standard deviation & 0.74 & 0.44 \\
\hline Variation coefficient & $6.3 \%$ & $3.5 \%$ \\
\hline Average increase & \multicolumn{2}{|c|}{0.96} \\
\hline Changes are reliable & \multicolumn{2}{|l}{} \\
\hline Error probability $<0.05$ & \multicolumn{2}{|l|}{} \\
\hline
\end{tabular}

For statistical analyses (see table 4) athlete's heart rate drops from values of beats per minute (bpm) were converted in percentage values. To create descriptive statistics athlete's heart rate drops were compared (heart rate drops in the worst test versus the best).

In Table 4, can be seen athlete's total heart rate drop as a percentage (compared with each athlete's worst and best test times). The total heart rate percentage drop improved only in 5 cases from 12. Despite demonstrating higher speed on kayak ergometer on blood lactate values 3mmol/l, 7 cases from 12 
showed a decrease in the total heart rate drop percentage values for athlete's (a $4,75 \%$ for $7^{\text {th }}$ athlete).

Table 4 Percentage drop of heart rate

\begin{tabular}{|c|c|c|}
\hline Athlete & $\begin{array}{c}\text { Heart rate drop (\%) in the lowest } \\
\text { functional test }\end{array}$ & $\begin{array}{c}\text { Heart rate drop (\%) in the best } \\
\text { functional test }\end{array}$ \\
\hline $1^{\text {st }}$ athlete & 39.69 & 40.21 \\
\hline $2^{\text {nd }}$ athlete & 41.54 & 37.31 \\
\hline $3^{\text {rd }}$ athlete & 39.11 & 36.04 \\
\hline $4^{\text {th }}$ athlete & 37.76 & 35.75 \\
\hline $5^{\text {th }}$ athlete & 42.86 & 42.21 \\
\hline $6^{\text {th }}$ athlete & 46.63 & 50.27 \\
\hline $7^{\text {th }}$ athlete & 43.41 & 38.66 \\
\hline $8^{\text {th }}$ athlete & 48.42 & 46.32 \\
\hline $9^{\text {th }}$ athlete & 43.16 & 41.67 \\
\hline $10^{\text {th }}$ athlete & 23.62 & 30.65 \\
\hline $11^{\text {th }}$ athlete & 36.73 & 41.75 \\
\hline $12^{\text {th }}$ athlete & 35.50 & 43.15 \\
\hline
\end{tabular}

The highest heart rate drop is observed for $6^{\text {th }}$ athlete $-50.27 \%$ and the lowest heart rate drop for $10^{\text {th }}$ athlete $-23.62 \%$. In two cases, the total heart rate improved more than $7 \%$. These cases were for the $10^{\text {th }}$ athlete and for the $12^{\text {th }}$ athlete with 7.03\% and 7.65 improvement, respectively.

Descriptive statistics determined that the coefficients of variation are $16.1 \%$ and $12.8 \%$, respectively (see table 5 ).

Table 5 Descriptive statistics of heart rate percentage drop

\begin{tabular}{|l|c|c|}
\hline & At the worst test & At the best test \\
\hline Average arithmetic & 39.87 & 40.33 \\
\hline Standard deviation & 6.41 & 5.18 \\
\hline Variation coefficient & $16.1 \%$ & $12.8 \%$ \\
\hline Asymmetry indicator & -1.395 & 0.090 \\
\hline Excess indicator & 3.247 & 0.520 \\
\hline Asymmetry $t$-test $(t<3)$ & 2.190 & 0.142 \\
\hline Excess t-test $(t<3)$ & 2.635 & 0.422 \\
\hline Compliance with a normal distribution & yes & yes \\
\hline
\end{tabular}

As coefficient of variation $>10 \%$ and the group is not uniform. This can be explained by the individual indicators of each athlete - every individual has specifically his own individual indicators (Bangsbo, Mohr, Poulsen, PerezGomez, \& Krustrup, 2006; Shlyk, 2016). Average arithmetic heart rate drops in lowest test (when athletes demonstrated the lowest speed on kayak ergometer at 
a blood lactate value $3 \mathrm{mmol} / \mathrm{l}$ ) was $39.87 \%$ and at the best test $40.33 \%$. The increase between average arithmetic heart rate drops is $0.46 \%$. Descriptive statistics show that the trait to be studied, in this case, the total heart rate drop (\%), varies according to the law of a normal distribution. Therefore, the Wilcoxon's criterion may be used to check the credibility of the difference (see table 6).

Table 6 Analysis of heart rate drop by Wilkinson's criterion

\begin{tabular}{|l|c|c|}
\hline & $\begin{array}{c}\text { Lowest functional } \\
\text { condition }\end{array}$ & $\begin{array}{c}\text { Highest functional } \\
\text { condition }\end{array}$ \\
\hline Average arithmetic & 39.87 & 40.33 \\
\hline Standard deviation & 6.41 & 5.18 \\
\hline Variation coefficient & $16.1 \%$ & $12.8 \%$ \\
\hline Standard error & 1.85 & 1.49 \\
\hline Average increase & \multicolumn{2}{|c|}{0.46} \\
\hline Changes are unreliable & \multicolumn{2}{|l}{} \\
\hline
\end{tabular}

Wilcoxon's criterion shows an average increase of $0.46 \%$, but changes are not reliable $\mathrm{T}>T_{\alpha ; v}$. The criterion indicates that sample differences are random.

\section{Discussion}

According to studies by (Wilmore et al., 1996) the effects of endurance training is beneficial for athletes, because the heart rate curve adapts, and its values are on a lower level. Reduction of the heart rate indicates that the heart works more efficiently as a result of training. To perform the necessary functions under the loads, a more developed, trained heart will do much less work than an untrained heart. Studies (Borg \& Linderholm, 1967; Skinner, 1973; Stamford, 1976; Eston \& Williams, 1986) confirm that there is a linear relationship between heart rate and load intensity.

The heart rate recovery in presented study shows different results comparing with Platonov (2004), where heart rate recovery rates of high-class freestyle wrestler were showed during different training periods, with changes in heart rate recovery curve.

This study was performed on professional male athletes (canoe sprint athletes). In this sport, extremely high endurance capabilities are combined with high strength. As for freestyle wrestling, it is more strength and power-oriented sport. The results of the study reflect heart rate recovery peculiarities in cyclic endurance sport. The main results showed, when the athletes get to a certain level of physical condition of their recovery rates in different training periods do not change significantly. Research shows that heart rate recovery after maximum 
oxygen consumption test for research subjects (kayakers) does not change significantly (even in different training periods and functional conditions).

\section{Conclusions}

In this paper, the heart rate recovery and functional condition of the professional canoe sprint athlete after maximum oxygen consumption test were studied. The heart rate recovery was measured in one-minute time periods up to four minutes after maximum oxygen consumption tests. In total, 43 tests were performed. Moreover, the functional condition was determined as a maximal speed on kayak ergometer at a blood lactate $3 \mathrm{mmol} / \mathrm{l}$. The differences between the worst and the best performance for each athlete were compared and analysed. The following main concussions are drawn:

- The total heart rate drop (decline) for athletes after maximum oxygen consumption test, comparing to the highest and the lowest functional condition (demonstrated speed on kayak ergometer at a blood lactate $3 \mathrm{mmol} / \mathrm{l}$ ), increased in $41.7 \%$ cases.

- Wilcoxon criterion indicates that the heart rate parameters (heart rate, total percentage drop) for athletes after maximum oxygen consumption tests that show improvement in an aspect of physical condition (demonstrated speed on kayak ergometer at a blood lactate 3mmol/l) changed (increased) by $0.46 \%$. However, the criterion indicates that the sample, in this case the heart rate drop (in percentage) differences are not reliable.

- The differences between the worst and the best performance of the tests for every athlete is different, values vary from 0.2 to $2.2 \mathrm{~km} / \mathrm{h}$. Converting these values to $1 \mathrm{~km}$ race the total decrease in time would be from 8 to $75 \mathrm{sec}$.

- $\quad$ Student t-test for related selections and after Wilcoxon's criterion athletes show an increase in speed on kayak ergometer at a blood lactate concentrations $3 \mathrm{mmol} / \mathrm{l}$. By comparing the worst test with the best, it can be seen an average increase of $0.96 \mathrm{~km} / \mathrm{h}$. Average growth in the speed is considered being reliable and the group status of a fundamental change.

\section{References}

Amano, M., Kanada, T., Ue.H., \& Moritani, T. (2001). Exercise training and autonomic nervous system activity in obese individuals. Medicine \& Science in Sports \& Exercise, 33(8), 1287-1291. 
Baldari, C., \& Guidetti, L. (2000). A simple method for individual anaerobic threshold as predictor of max lactate steady state. Medicine \& science in sports \& exercise, 32(10), 1798-1802.

Bangsbo, J., Mohr, M., Poulsen, A., Perez-Gomez, J., \& Krustrup, P. (2006). Training and testing the elite athlete. J Exerc Sci Fit, 4(1), 1-14.

Banister, E.W., \& Calvert, T.W. (1980). Planning for future performance: implications for long term training. Canadian journal of applied sport sciences. Journal canadien des sciences appliquees au sport, 5(3), 170-176.

Borg, G., \& Linderholm, H. (1967). Perceived exertion and pulse rate during graded exercise in various age groups". ActaMed.Scand, (Suppl. 472), 194-206.

Bourdon, P.C., Cardinale, M., Murray, A., Gastin, P., Kellmann, M., Varley, M.C., ... \& Cable, N.T. (2017). Monitoring athlete training loads: consensus statement. International journal of sports physiology and performance, 12(s2), S2-161.

Carter, J.B., Banister, E.W., \& Blaber, A.P. (2003). Effect of endurance exercise on autonomic control of heart rate. Sports medicine, 33(1), 33-46.

Dansprint.com. (n.d.). TECHNICAL INFORMATION - Dansprint UK. [online] Retrieved from http://www.dansprint.com/uk/DANSPRINT-ERGOMETERS/TECHNICALINFORMATION.html

Dixon, E.M., Kamath, M.V., McCartney, N., \& Fallen, E.L. (1992). Neural regulation of heart rate variability in endurance athletes and sedentary controls. Cardiovascular research, 26(7), 713-719.

Eston, R.G., \& Williams, J.G. (1986). Exercise intensity and perceived exertion in adolescent boys. British journal of sports medicine, 20(1), 27-30.

Faria, E.W., Parker, D.L., \& Faria, I.E. (2005). The Science of Cycling. Sports Medicine, 35(4), 285-312.

Faude, O., Kindermann, W., \& Meyer, T. (2009). Lactate threshold concepts. Sports medicine, 39(6), 469-490.

Greiwe, J.S., Hickner, R.C., Hansen, P.A., Racette, S.B., Chen, M.M., \&Holloszy, J.O. (1999). Effects of endurance exercise training on muscle glycogen accumulation in humans. Journal of Applied Physiology, 87(1), 222-226.

HaB Direct. (n.d.). EKF Diagnostics Biosen Blood Glucose/Lactate Analyser | HaB Direct. [online] Retrieved from http://www.habdirect.co.uk/biosen-c-line-glucose-and-lactateanalysers .

Hall, E.J., \& Guyton, C.A. (2006). Guyton and Hall textbook of medical physiology: 12th edition. Elsevier Inc. 1600 John F. Kennedy Blvd., Suite 1800 Philadelphia, Pennsylvania 19103-2899

Iwasaki, K.I., Zhang, R., Zuckerman, J.H., \& Levine, B.D. (2003). Dose-response relationship of the cardiovascular adaptation to endurance training in healthy adults: how much training for what benefit?. Journal of Applied Physiology, 95(4), 1575-1583.

Javorka, M., Zila, I., Balharek, T., \&Javorka, K. (2002). Heart rate recovery after exercise: relations to heart rate variability and complexity. Brazilian Journal of Medical and Biological Research, 35(8), 991-1000. (par heart rate recovery)

Jones, A.M. (2006). The physiology of the world record holder for the women's marathon. International Journal of Sports Science \& Coaching, 1(2), 101-116.

Kannankeril, P.J., Le, F.K., Kadish, A.H., \& Goldberger, J.J. (2004). Parasympathetic effects on heart rate recovery after exercise. Journal of investigative medicine, 52(6), 394-401.

Karvonen, J., \& Vuorimaa, T. (1988). Heart rate and exercise intensity during sports activities. Sports Medicine, 5(5), 303-311. 
Kindermann, W., Simon, G., \& Keul, J. (1979). The significance of the aerobic-anaerobic transition for the determination of work load intensities during endurance training. European journal of applied physiology and occupational physiology, 42(1), 25-34.

Lambert, M.I., \& Borresen, J. (2010). Measuring training load in sports. International journal of sports physiology and performance, 5(3), 406-411.

Lambert, M.I., Mbambo, Z.H., \& Gibson, A.S.C. (1998). Heart rate during training and competition for longdistance running. Journal of sports sciences, 16(sup1), 85-90.

Laukkanen, R.M., \& Virtanen, P.K. (1998). Heart rate monitors: state-of-the art. Journal of sports sciences, 16(sup1), 3-7.

Mann, T., Lamberts, R.P., \& Lambert, M.I. (2013). Methods of prescribing relative exercise intensity: physiological and practical considerations. Sports medicine, 43(7), 613-625.

Nims, J., Capozzi, M., Hailey, M.B., \& Crankson, K. (2018). U.S. Patent No. 9,895,096. Washington, DC: U.S. Patent and Trademark Office.

Platonov, V.N. (2004). Otbor i orientacija sportsmenov $v$ sisteme mnogoletnej podgotovki. Sistema podgotovki sportsmenov $v$ olimpijskom sporte. Kiev: Olimpijskaja literatura, 524-558.

Stegmann, H., \& Kindermann, W. (1982). Comparison of prolonged exercise tests at the individual anaerobic threshold and the fixed anaerobic threshold of $4 \mathrm{mmol} \mathrm{L}-1$ lactate. International journal of sports medicine, 3(02), 105-110.

Seiler, S., Haugen, O., \& Kuffel, E. (2007). Autonomic recovery after exercise in trained athletes: intensity and duration effects. Medicine \& Science in Sports \& Exercise, 39(8), 1366-1373. (arī par HR recovery)

Shin, K., Minamitani, H., Onishi, S., Yamazaki, H., \& Lee, M. (1995a). The power spectral analysis of heart rate variability in athletes during dynamic exercise-Part I. Clinical cardiology, 18(10), 583-586.

Shin, K., Minamitani, H., Onishi, S., Yamazaki, H., \& Lee, M. (1995b). The power spectral analysis of heart rate variability in athletes during dynamic exercise-Part II. Clinical cardiology, 18(11), 664-668.

Shlyk, N.I. (2016). Management of athletic training taking into account individual heart rate variability characteristics. Human Physiology, 42(6), 655-664.

Skinner, J.S., \& Mclellan, T.H. (1980). The transition from aerobic to anaerobic metabolism. Research quarterly for exercise and sport, 51(1), 234-248.

Skinner, J.S., Hustler, R., Bergsteinova, V., \& Buskirk, E.R. (1973). Perception of effort during different types of exercise and under different environmental conditions. Med. \& Sci. in Sports, 5, 110-115.

Smith, M.L., Hudson, D.L., Graitzer, H.M., \& Raven, P.B. (1989). Exercise training bradycardia: the role of autonomic balance. Medicine and science in sports and exercise, 21(1), 40-44.

Stamford, B.A. (1976). Validity and reliability of subjective ratings of perceived exertion during work. Ergonomics, 19, 53-60.

Support.polar.com. (n.d.). [online] Retrieved from https://support.polar.com/support_files/ en/C225742500419A8A42256BED00225FD1/Manual\%20M91ti+\%20USAGBR\%20A.pdf

Wilmore, J.H., Stanforth, P.R., Gagnon, J., Leon, A.S., Rao, D.C., Skinner, J.S., \& Bouchard, C. (1996). Endurance exercise training has a minimal effect on resting heart rate: the HERITAGE Study. Medicine \& Science in Sports \& Exercise, 28(7), 829-835. 
SOCIETY. INTEGRATION. EDUCATION

Proceedings of the International Scientific Conference. Volume VI, May $22^{\text {th }}-23^{\text {th }}, 2020.430-444$

Yamamoto, K., Myachi, M., Saitoh, T., Yoshioka, A., \& Onodera, S. (2001). Effects of endurance training on resting and post-exercise cardiac autonomic control. Medicine \& Science in Sports \& Exercise, 33(9), 1496-1502. 